Journal of Telenursing (JOTING)

Volume 1, Nomor 1, Juni 2019

e-ISSN : 2684-8988

p-ISSN : 2684-8996

DOI: https://doi.org/10.31539/joting.v1i1.497

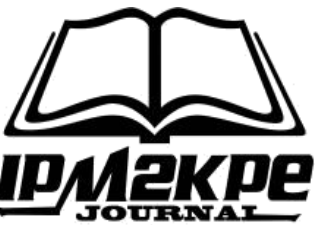

\title{
PERBANDINGAN SENAM TAI CHI DAN SENAM DIABETES MELLITUS TERHADAP PENURUNAN KADAR GULA DARAH PADA PASIEN DIABETES MELLITUS TIPE II
}

\author{
Rika Srywahyuni ${ }^{1}$, Agung Waluyo ${ }^{2}$, Rohman Azzam ${ }^{3}$ \\ Universitas Muhammadiyah Jakarta ${ }^{1,3}$ \\ Universitas Indonesia ${ }^{2}$ \\ rika.februari1@gmail.com ${ }^{1}$
}

\begin{abstract}
ABSTRAK
Penelitian ini bertujuan mengetahui perbandingan senam tai chi dan senam DM terhadap penurunan kadar gula darah pasien DM tipe II di Puskesmas Menjalin. Desain penelitian yang digunakan adalah quasi eksperimen dengan pendekatan pre and post test group design. Hasil penelitian dengan menggunakan uji wilcoxon pada kelompok tai chi didapatkan nilai $\mathrm{p}=0,000<\alpha=0,05$ dan hasil uji t-test paired sample test pada senam diabetes mellitus didapatkan nilai $p=0,000<\alpha=0,05$. Simpulan, senam tai chi dan senam DM sama-sama berpengaruh dalam menurun kan kadar gula darah pasien diabetes mellitus tipe II, namun dilihat dari selisih penurunan kadar gula darah senam Diabetes Mellitus lebih efektif dari senam Tai Chi.
\end{abstract}

Kata Kunci : Kadar Gula Darah, Senam Diabetes Mellitus, Senam Tai Chi

ABSTRACT

This study aims to determine the comparison of Tai Chi and DM exercises to reduce blood sugar levels in type II DM patients at Menjalin Health Center. The research design used was a Quasi experiment with a pre and post test group design approach. The results of the study using the Wilcoxon test in the Tai Chi group obtained the value of $p=0.000<\alpha=$ 0.05 and the results of the t-test paired sample test on diabetes mellitus exercise obtained $p$ $=0.000<\alpha=0.05$. In conclusion, Tai Chi and DM exercises are equally influential in reducing blood sugar levels in type II diabetes mellitus patients, however, seen from the difference in decreasing blood sugar levels, Diabetes Mellitus exercise is more effective than Tai Chi exercise.

Keywords: Blood Sugar Levels, Diabetes Mellitus Exercise, Tai Chi Exercise

\section{PENDAHULUAN}

Diabetes Melitus merupakan salah satu jenis penyakit metabolik yang ditandai dengan tingginya kadar gula darah akibat dari kurangnya sekresi insulin, yang mengalami peningakatan disetiap tahunnya di negaranegara seluruh dunia. Menurut IDF (Internasional of Diabetic Ferderation) tingkat prevalensi penderita DM tahun 2014 sebesar 8,3 \% dari 
keseluruhan penduduk di dunia, tahun 2015 sebanyak 415 juta orang dewasa dengan diabetes mengalami kenaikan 4 kali lipat dari 108 juta di 1980an. Diperkirakan pada tahun 2040 jumlah penderita DM akan meningkat menjadi 642 juta, tahun 2015 presentase penderita diabetes sebesar 8,5\% (IDF Atlas 2015).

Perkumpulan endokrinologi (PERKENI) menyatakan jumlah penderita diabetes di Indonesia telah mencapai 9,1 juta orang. Indonesia disebut telah bergeser naik, dari peringkat ke-7 menjadi peringkat ke -5 teratas diantara negara-negara dengan jumlah penderita diabetes terbanyak dunia. Masalah yang dihadapi oleh Indonesia yaitu, belum semua penderita DM mendapatkan akses ke pusat pelayanan kesehatan secara memadai. Demikian juga kemampuan petugas kesehatan yang belum optimal dalam menangani kasus-kasus DM, baik dalam aspek preventif, promotif, kuratif dan rehabilitatif (Perkeni, 2015).

Prevalensi penyakit DM di provinsi Kalimantan Barat berdasarkan diagnosis dokter di Indonesia pada tahun 2013 sebesar 0,8 \% (Pusdatin, 2014). Kabupaten Landak merupakan suatu kabupaten/ kota daerah yang bermasalah dengan kesehatan, salah satunya yaitupenyakit diabetes mellitus, dikarenakan gaya hidup masyarakat yang berubah lebih sering mengkonsumsi minuman manis dan kurangnya kesadaraan masyarakat untuk melakukan aktifitas fisik seperti berolahraga, puskesmas Menjalin merupakan salah satu puskesmas yang ada di kabupaten Landak berdasarkan data primer yang di dapat pada tahun 2017 penyakit DM masuk dalam 10 urutan penyakit terbanyak yang diderita olehmasyarakat yang berada di lingkungan puskesmas Menjalin, jumlah penyandang DM pada tahun 2017 yaitu sebanyak 1.800 jiwa.

Melihat angka kejadian diabetes secara global yang disebabkan karena meningkatnya kemakmuran suatu populasi, maka dapat dimengerti bila suatu saat dalam kurun waktu 10 atau 20 tahun yang akan datang penyakit DM Tipe II di Indonesia akan meningkat dengan drastis, yang disebabkan oleh beberapa faktor :faktor keturunan (genetik), faktor kegemukan/obesitas (perubahan gaya hidup dari tradisional ke gaya barat, makan berlebihan, kurang gerak badan dan hidup santai) faktor demografi (jumlah penduduk meningkat, urbanisasi, penduduk berumur diatas 40 tahun meningkat) (Soegondo, 2009). DM jika tidak dikelola dengan baik maka akan menimbulkan komplikasi akut dan kronik. Pada pasien DM sel-sel di dalam tubuh berhenti berespon terhadap insulin atau pankreas berhenti memproduksi insulin, hal ini mengakibatkan hiperglikemia sehingga dalam waktu tertentu dapat menyebabkan komplikasi metabolik akut, selain itu dalam jangka panjang hiperglikemia menyebabkan komplikasi makrovaskular, komplikasi mikrovaskular dan komplikasi neuropatik (Smeltzer \& Bare, 2008). Adapun cara pencegahan komplikasi pada penderita DM yaitu dengan melakukan kontrol kadar gula darah, memeriksa rutin kadar gula darah, mengkonsumsi obat hipoglikemi, patuh dalam diit rendah kalori dan latihan fisik ringan.

Adapun cara pencegahan komplikasi pada penderita DM yaitu dengan melakukan kontrol kadar gula darah, memeriksa rutin kadar gula darah, mengkonsumsi obat hipoglikemi, patuh dalam diit rendah kalori dan latihan fisik ringan. Anjuran untuk olahraga bagi diabetisi bukan merupakan hal yang baru, meskipun sudah ada beberapa penelitian tentang hal ini namun para ahli yang berkecimpung di bidang ini sadar bahwa penelitian mengenai manfaat olahraga bagi diabetisi masih sangat terbatas. Olahraga yang 
teratur bersama dengan diet yang tepat dan penurunan berat badan merupakan penatalaksanaan diabetes yang dianjurkan terutama bagi DM tipe 2 (Soegondo, 2009).

Latihan yang dianjurkan untuk menurunkaan kadar gula darah yaitulatihan yang bersifat aerobik seperti: jalan kaki, jogging, senam, bersepeda santai, dan berenang. Latihan jasmani sebaiknya disesuaikan dengan umur dan status kesehatan penderita DM (Perkeni, 2011). Salah satu olahraga yang bisa dilakukan oleh penderita DM yaitu dengan melakukan senam, yang dipercaya dapat menurunkan kadar gula darah diantaranya adalah senam tai chi dan senam DM. Latihan Tai Chi merupakan latihan tradisional dari Cina yang menggabungkan latihan pernafasan, rileksasi, dan struktur gerakan yang pelan dan lembut, senam Tai Chi juga dipercaya dapat menjadi alternatif untuk meredakan stress (Anwar, 2011).

Senam Tai Chi merupakan bentuk olah tubuh yang bermanfaat bagi kesehatan, yang merupakan latihan atau gerakkan olahraga penggabungan antara gerakan tubuh, olah pernafasan dan juga meditasi. Sedangkan Senam diabetes adalah aerobic low impact dengan ritmis dan gerakan yang menyenangkan dan tidak membosankan yang dapat meningkatkan kesegaran jasmani. Senam diabetes dapat melancarkan sirkulasi darah, mengontrol kadar gula darah, menurunkan resistensi insulin dan meningkatkan sensitivitas insulin di otot (Santoso, 2008).

Penelitian yang dilakukan oleh Agik (2016) di wilayah kelurahan Polehan kota Malang membuktikan bahwa Tai Chi efektif dalam menurunkan kadar gula darah penderita DM tipe 2. Selanjutnya penelitian yang dilakukan oleh Agus diwilayah kerja puskesmas Peterongan Jombang membuktikan bahwa senam DM dapat menurunkan kadar gula darah dengan latihan yang dilakukan secara rutin. Berdasarkan data-data yang telah dijabarkan diatas penulis tertarik untuk melakukan penelitian tentang "Perbandingan Senam Tai Chi dan Senam Diabetes Mellitus Terhadap Penurunan Kadar Gula Darah pada Pasien Diabetes Mellitus Tipe II di Wilayah Kerja Puskesmas Menjalin”.

\section{METODE PENELITIAN}

Jenis penelitian yang digunakan adalah penelitian kuantitatif, desain penelitian menggunakan metode quasi eksperimen dengan pendekatan pre and post test group design.

Peneliti akan membandingkan senam tai chi dan senam diabetes mellitus dalam menurunkan kadar gula darah pada penderita DM tipe II. Alat penelitian yang digunakan adalah glukometer untuk pemeriksaan kadar glukosa darah, lembar observasi pelaksanaan senam tai chi dan lembar observasi pelaksanaan senam DM serta hasil pengukuran kadar glukosa darah.

Teknik pengambilan sampel dalam penelitian ini dengan menggunakan purposive sampling yaitu pemilihan dengan menetapkan subyek yang memenuhi kriteria penelitian di masukan dalam penelitian sehingga sample terpenuhi. Sampel yang digunakan untuk setiap kelompok dalam penelitian ini sebanyak 16 orang dan jumlah kelompok yang digunakan yaitu 2 kelompok sehingga penelitian ini menggunakan 32 orang responden dari populasi yang ada, yang dibagi dalam 2 kelompok intervensi, dimana kelompok intervensi pertama diberikan senam Tai Chi dan kelompok intervensi kedua diberikan senam DM. 
Pengambilan data pada responden dilaksanakan dengan melakukan pemilihan responden yang sesuai dengan kriteria inklusi sebanyak 32 responden dengan teknik purposive sampling yang di bagi dalam 2 kelompok intervensi. Peneliti membagi berdasarkan nomor ganjil dan genap nomor urut dari responden yang sudah diambil berdasarkan kriteria inklusi peneliti. Nomor ganjil untuk intervensi Tai Chi sedangkan genap untuk intervensi senam DM. Pengambilan data responden dilakukan setelah pasien menyatakan bersedia menjadi responden dalam penelitian ini.

Setelah pengambilan data, pasien diberikan penjelasan tentang tujuan, manfaat penelitian dan prosedur penelitian yang akan dilaksanakan. Kelompok Intervensi satu diberikan perlakuan senam Tai Chi, pelaksanaan nya seminggu tiga kali selama dua minggu yang dilakukan pada hari senin, rabu dan jumat, kemudian dilakukan pencatatan kadar gula darah pre sebelum dilakukan senam dan post pada hari terakhir setelah dilakukan senam tai chi pada format yang tersedia. Kelompok Intervensi dua diberikan perlakuan senam DM pelaksanaannya seminggu tiga kali selama dua minggu yang dilakukan pada hari selasa, kamis dan sabtu, kemudian dilakukan pencatatan kadar gula darah pre hari pertama sebelum senam dan post pada hari terakhir setelah senam pada format yang tersedia.

\section{HASIL PENELITIAN}

Tabel. 1

Distribusi Frekuensi Berdasarkan Usia Responden $(\mathrm{n}=32)$

\begin{tabular}{|c|c|c|c|c|c|}
\hline \multirow[t]{2}{*}{ Variabel } & \multicolumn{2}{|c|}{$\begin{array}{c}\text { Intervensi senam } \\
\text { Tai chi }(n=16)\end{array}$} & \multicolumn{2}{|c|}{$\begin{array}{c}\text { Intervensi senam DM } \\
(\mathrm{n}=16)\end{array}$} & \multirow[t]{2}{*}{ Tota } \\
\hline & $\mathrm{f}$ & $\%$ & $\mathrm{f}$ & $\%$ & \\
\hline \multicolumn{6}{|l|}{ Usia } \\
\hline $36-45$ tahun & & & 4 & $25.0 \%$ & 4 \\
\hline 46-55 tahun & 5 & $31.3 \%$ & 6 & $37.5 \%$ & 11 \\
\hline 56-65 tahun & 8 & $50.0 \%$ & 3 & $18.8 \%$ & 11 \\
\hline 66-75 tahun & 3 & $18.8 \%$ & 3 & $18.8 \%$ & 6 \\
\hline
\end{tabular}

Sumber: Data Primer 2018

Berdasarkan tabel 1 dapat dilihat bahwa pada kelompok intervensi senam Tai Chi paling banyak responden berusia 56-65 tahun yaitu 8 responden (50.0\%). Adapun usia 4655 sebanyak 5 responden $(31.3 \%)$ dan usia $66-75$ ada 3 responden (18.8\%). Sedangkan pada kelompok intervensi senam DM paling banyak di usia 46-55 tahun yaitu 6 responden, dan usia 36-45 tahun 4 responden $(25.0 \%)$ untuk usia 56-65 sebanyak 3 responden (18.8\%) dan usia 66-75 tahun 3 responden (18.8\%). Dari data diatas disimpulkan bahwa usia responden paling banyak menderita DM pada senam tai chi dan senam diabetes mellitus adalah usia 46-65 tahun. 
Tabel. 2

Distribusi Frekuensi Berdasarkan Jenis Kelamin Responden ( $\mathrm{n}=32)$

\begin{tabular}{|c|c|c|c|c|c|}
\hline \multirow[t]{2}{*}{ Variabel } & \multicolumn{2}{|c|}{$\begin{array}{l}\text { Intervensi senam } \\
\text { Tai chi }(\mathrm{n}=16)\end{array}$} & \multicolumn{2}{|c|}{$\begin{array}{l}\text { Intervensi senam DM } \\
\qquad(\mathrm{n}=16)\end{array}$} & \multirow[t]{2}{*}{ Total } \\
\hline & $\mathrm{f}$ & $\%$ & $\mathrm{f}$ & $\%$ & \\
\hline \multicolumn{6}{|l|}{ Jenis Kelamin } \\
\hline Laki-laki & 3 & $18,8 \%$ & 5 & $31,3 \%$ & 8 \\
\hline Perempuan & 13 & $81,3 \%$ & 11 & $68,8 \%$ & 24 \\
\hline
\end{tabular}

Berdasarkan tabel 2 dapat dilihat bahwa pada kelompok intervensi Tai Chi paling banyak yaitu responden berjenis kelamin perempuan 13 responden $(81,3 \%)$ dan responden laki-laki sebanyak 3 responden $(18,8 \%)$. Sedangkan pada kelompok intervensi senam DM responden paling banyak berjenis kelamin perempuan 11 responden $(68,8 \%)$ dan responden laki-laki 5 responden $(31,3 \%)$. Dari data diatas maka disimpulkan bahwa berdasarkan distribusi frekuensi jenis kelamin responden yang menderita DM pada kelompok senam Tai Chi dan senam diabetes Mellitus lebih banyak didominasi oleh responden perempuan.

Tabel. 3

Distribusi Frekuensi Berdasarkan Lama Menderita Diabetes Mellitus ( $\mathrm{n}=32)$

\begin{tabular}{lccccc}
\hline \multirow{2}{*}{ Variabel } & \multicolumn{2}{c}{$\begin{array}{c}\text { Intervensi senam } \\
\text { Tai chi }(\mathrm{n}=16)\end{array}$} & \multicolumn{2}{c}{$\begin{array}{c}\text { Intervensi senam DM } \\
(\mathrm{n}=16)\end{array}$} & \multirow{2}{*}{ Total } \\
\cline { 2 - 4 } & $\mathrm{F}$ & $\%$ & $\mathrm{f}$ & $\%$ & \\
\hline Lama sakit & 6 & $37,5 \%$ & 9 & $56.3 \%$ & 15 \\
$<5$ tahun & 10 & $62,5 \%$ & 7 & $43.8 \%$ & 17 \\
\hline 5 tahun & 10 & & & \\
\hline
\end{tabular}

Sumber: Data Primer Tahun 2018

Berdasarkan tabel 3 dapat dilihat bahwa lama menderita DM pada kelompok intervensi senam Tai Chi lebih banyak diatas 5 tahun yaitu 10 responden $(62,5 \%)$ dan yang kurang 5 tahun sebanyak 6 responden (37,5\%). Sedangkan distribusi lama menderita DM pada kelompok intervensi senam DM paling banyak lama menderita DM kurang dari 5 tahun yaitu 9 responden $(56.3 \%)$ dan yang lebih dari 5 tahun sebanyak 7 responden (43.8\%). Dari data diatas disimpulkan bahwa lama menderita DM paling banyak yaitu responden yang lama menderita DM lebih dari 5 tahun.

Tabel. 4

Rata-Rata Kadar Gula Darah Sebelum dan Sesudah Intervensi pada Kelompok Senam Tai Chi dan Senam Diabetes Mellitus ( $\mathrm{n}=32)$

\begin{tabular}{cccccc}
\hline Kelompok & N & Mean & SD & Min-Mak & $95 \%$ \\
\hline Sebelum & \multicolumn{5}{c}{ Kelompok Intervensi Senam Tai Chi } \\
Sesudah & 16 & 219.44 & 28,872 & $173-262$ & $205,63-232,62$ \\
& 16 & 208.13 & 28,577 & $160-251$ & $194,38-221,12$ \\
\hline
\end{tabular}




\begin{tabular}{|c|c|c|c|c|c|}
\hline \multicolumn{6}{|c|}{ Kelompok Intervensi Senam DM } \\
\hline Sebelum & 16 & 217,31 & 30,925 & $182-301$ & $204,00-233,56$ \\
\hline Sesudah & 16 & 193,94 & 24,532 & $165-260$ & $182,70-205,99$ \\
\hline
\end{tabular}

Sumber : Data Primer Tahun 2018

Berdasarkan tabel 4 menunjukkan bahwa rata-rata kadar gula darah pada kelompok intervensi senam Tai Chi sebelumnya adalah $219,44 \mathrm{mg} / \mathrm{dl}$ dengan SD 28,872 dan setelah dilakukan senam Tai Chi menjadi 208,00 mg/dl dengan SD 28,577. Sedangkan rata-rata untuk kelompok senam diabetes mellitus sebelumnya adalah $217,31 \mathrm{mg} / \mathrm{dl}$ dengan SD 30,925 dan setelah dilakukan senam diabetes mellitus menjadi 193,94 mg/dl dengan standar deviasi 24,532.

Tabel. 5

Hasil Uji Normalitas Data pada Variabel Kadar Gula Darah pada Kelompok Intervensi Tai Chi $(\mathrm{n}=32)$

\begin{tabular}{ccccc}
\hline Kelompok & Mean & SD & n & $p$ value \\
\hline Senam Tai chi & 11,31 & 3,09 & 16 & 0,048 \\
\hline
\end{tabular}

Sumber :Data Primer 2018

Berdasarkan tabel 5 setelah dilakukan uji normalitas pada kadar gula darah sebelum dan sesudah intervensi senam tai chi didapatkan nilai $p$ value sebesar 0,048 dimana $p$ value lebih kecil dari 0,05 maka data dikatakan berdistribusi tidak normal, untuk menormalkan data selanjutnya dilakukan uji transformasi data.

Tabel. 6

Transformasi Data Senam Tai Chi

\begin{tabular}{ccccc}
\hline Kelompok & Mean & SD & $\mathrm{n}$ & $\begin{array}{c}p \text { Value } \\
\text { Transformasi data }\end{array}$ \\
\hline KGD Tai chi & 1,03 & 0,144 & 16 & 0,006 \\
\hline Sumber $:$ Data Primer 2018 & & &
\end{tabular}

Sumber :Data Primer 2018

Setelah dilakukan transformasi data didapatkan $\mathrm{p}$ value sebesar 0,006 dimana nilai $\mathrm{p}$ lebih kecil dari 0,05 setelah dilakukan transformasi data tetap berdistribusi tidak normal, maka untuk melanjutkan ke uji bivariat untuk menguji hipotesis pada variabel senam tai chi dilakukan uji non parametric (Wilcoxon) .

Tabel. 7

Hasil Uji Normalitas Data pada Variabel Kadar Gula Darah pada Kelompok Intervensi Senam Diabetes Mellitus $(\mathrm{n}=32)$

\begin{tabular}{ccccc}
\hline Kelompok & Mean & SD & n & p value \\
\hline Senam DM & 23,38 & 13.31 & 16 & $0,057^{*}$
\end{tabular}


Setelah dilakukan uji normalitas pada kadar gula darah sebelum dan sesudah intervensi senam senam diabetes mellitus didapatkan nilai $p$ value sebesar 0,057 dimana $p$ value lebih besar dari 0,05 maka data disimpulkan berdistribusi normal, untuk melanjutkan ke tahap analisis bivariat maka uji yang digunakan yatu uji parametik (paired t test).

Tabel. 8

Perbedaan Kadar Gula Darah Sebelum dan Sesudah

Senam Tai Chi

\begin{tabular}{ccc}
\hline & Median (min-max) & Nilai $\mathrm{p}$ \\
\hline $\begin{array}{c}\text { KGD sebelum intervensi } \\
(\mathrm{n}=16)\end{array}$ & $223,50(173-262)$ & \\
\hline $\begin{array}{c}\text { KGD sesudah intervensi } \\
(\mathrm{n}=16)\end{array}$ & $212,00(160-251$ & $0,000^{*}$ \\
\hline Sumber : Data Primer 2018 & &
\end{tabular}

Berdasarkan tabel 8 menunjukkan bahwa perbandingan kadar gula darah sebelum intervensi adalah $223.50 \mathrm{mg} / \mathrm{dl}$ dan sesudah dilakukan intervensi menjadi 212,00 mg/dl. Terdapat 32 orang responden dengan hasil kadar gula darah lebih rendah dari pada sebelum senam tai chi diberikan, hasil uji wilcoxon menunjukkan nilai $(\mathrm{p}=0,000)$ karena nilai $\mathrm{p}<0,05$ secara statistik terdapat perbedaan kadar gula darah yang bermakna antara sebelum dan sesudah dilakukan senam tai chi. Terdapat perbedaan kadar gula darah yang bermakna antara sebelum senam dengan sesudah dilakukan senam tai chi.

Tabel. 9

Perbedaan Kadar Gula Darah Sebelum dan Sesudah

Senam DM

\begin{tabular}{lcccc}
\hline & Mean & Selisih & (I 95\%) & Nilai p \\
\hline KGD sebelum intervensi $(\mathrm{n}=16)$ & 217,31 & 23,37 & $16,282-30,468$ & $0,000^{*}$ \\
KGD sesudah intervensi $(\mathrm{n}=16)$ & 193,94 & & & \\
\hline
\end{tabular}

Sumber : Data Primer 2018

Berdasarkan tabel 9 menunjukkan rata-rata kadar gula darah pada kelompok senam DM sebelumnya adalah $217.31 \mathrm{mg} / \mathrm{dl}$ dan setelah dilakukan senam DM di dapatkan hasil kadar gula darah 193.94. Diperoleh nilai significancy 0,000 ( $p<0,05)$ dengan selisih 23,37, karena nilai $\mathrm{p}<0,05$ secara statistic terdapat perbedaan yang bermakna antara sebelum dan sesudah dilakukan senam diabetes mellitus.

Tabel. 10

Selisih Kadar Gula Darah Senam Tai Chi dan Senam Diabetes Mellitus (N=32)

\begin{tabular}{ccccc}
\hline & Sebelum & Sesudah & Selisih & Nilai p \\
\hline Intervensi Tai chi & 219,44 & 208,13 & 11,31 & $0,000^{*}$ \\
Intervensi senam DM & 217.31 & 193.94 & 23.37 & $0,000^{*}$ \\
\hline
\end{tabular}

Sumber : Data Primer 2018 
Berdasarkan tabel 10 didapatkan hasil selisih rata-rata kadar gula darah sebelum dan sesudah senam tai chi adalah $11.31 \mathrm{mg} / \mathrm{dl}$ dengan nilai p value 0,000. Sedangkan untuk intervensi senam diabetes mellitus di dapatkan selisih penurunan kadar gula darah setelah intervensi adalah 23,37 mg/dl dengan nilai $\mathrm{p}$ value 0,000 . Berdasarkan nilai $\mathrm{p}$ value yang di dapat antara senam tai chi dan senam diabetes mellitus sama-sama efektif dalam menurunkan kadar gula darah. Maka disimpulkan antara senam tai chi dan senam DM sama-sama berpengaruh dalam menurunkan kadar gula darah, tetapi dilihat dari hasil selisih penurunan kadar gula darah yang lebih banyak menurunkan kadar gula darah adalah senam diabetes mellitus dibandingkan dengan senam tai chi.

\section{PEMBAHASAN}

Berdasarkan hasil dari penelitian yang telah dilakukan didapatkan hasil yang menunjukkan bahwa sebagian besar responden penderita diabetes mellitus tipe 2 berusia diatas 46-65 tahun. Hal ini karena pada usia diatas 30 tahun adalah usia yang memiliki resiko terkena penyakit DM tipe 2 dan adanya perubahan anatomis, fisiologis dan biokimia. Perubahan dimulai dari tingkat sel, kemudian berlanjut pada tingkat jaringan dan akhirnya pada tingkat organ yang dapat mempengaruhi homeostasis. Setelah seseorang mencapai usia 40 tahun beresiko terkena DM disebabkan karena pada usia tersebut mulai terjadi peningkatan intoleransi glukosa. Adanya proses penuaan yang menyebabkan berkurangnya kemampuan sel beta pankreas dalam memproduksi insulin (Sujaya, 2009).

Menurut ADA (2010) seseorang yang paling sering menderita diabetes antara berumur 45-64 tahun, pada rentang tersebut dikaitkan dengan berbagai macam penyakit degenerative yang salah satunya adalah diabetes mellitus. Seiring bertambahnya usia tubuh mempunyai daya toleransi yang rendah terhadap glukosa. Kondisi ini disebabkan oleh perubahan reseptor glikoprotein yang akan membantu insulin mentransfer glukosa kedalam sel-sel otot, hepar, dan jaringan adipose mengalami penurunan sehingga timbul defisiensi respon terhadap insulin. Sekresi insulin tidak mengalami penurunan dengan bertambahnya usia, tetapi kepekaan reseptor yang berhubungan dengan insulin mengalami penurunan (Hembing, 2008). Sejalan dengan penelitian yang dilakukan oleh Rochmah (2006) menyatakan usia 50-70 tahun adalah usia yang sangat erat kaitannya dengan hiperglikemia. Peningkatan kadar glukosa darah pada usia lanjutdikarenakan resistensi insulin akibat terjadinya perubahan komposisi tubuh, menurunnya aktivitas, perubahan pada pola makan dan penurunan fungsi neurohormonal.

Berdasarkan prevalensi wanita dan pria mempunyai peluang yang sama terkena diabetes. Hanya saja dari faktor resiko, wanita lebih beresiko menderita diabetes karena secara fisik wanita memiliki peluang peningkatan indeks masa tubuh yang lebih besar. Selain itu pada wanita yang sedang hamil terjadi ketidakseimbangan hormonal, progesteron tinggi, sehingga meningkatkan sistem kerja tubuh untuk merangsang sel-sel berkembang (termasuk pada janin), tubuh akan memberikan sinyal lapar dan puncaknya menyebabkan sistem metabolisme tubuh tidak bisa menerima langsung asupan kalori, dan menggunakannya secara total, sehingga mengakibatkan terjadinya peningkatan kadar gula darah saat kehamilan (Damayanti, 2010).

Perempuan memiliki kecenderungan mengalami obesitas dibandingkan dengan lakilaki. Perempuan memiliki LDL tingkat trigliserida yang lebih tinggi dibandingkan dengan laki-laki, jumlah lemak pada laki-laki dewasa berkisar antara 15-20\% dari berat badan 
total, dan pada perempuan sekitar 20-25\%. Jadi peningkatan kadar lipid pada perempuan lebih tinggi dibandingkan pada laki-laki, sehingga faktor risiko terjadinya diabetes mellitus pada perempuan 3-7 kali lebih tinggi dibandingkan pada laki-laki yaitu 2-3 kali (Jelantik \& Haryati, 2014). Sesuai dengan pendapat Brunner \& Suddart (2008) menyebutkan bahwa perempuan lebih banyak mengidap diabetes mellitus dibandingkan laki-laki. Hal ini dipicu oleh adanya persentase timbunan lemak badan pada wanita yanglebih besar dibandingkan dengan laki-laki yang menjadi salah satu faktor yang dapat menurunkan sensitifitas terhadap kerja insulin pada otot dan hati.

Perempuan juga memiliki kecenderungan untuk mengalami diabetes terutama pasca menopause. Hal ini berkaitan dengan hormon estrogen dan progesterone yang mempengaruhi sel-sel tubuh dalam merespon insulin. Estrogen adalah hormon yang dimiliki perempuan, pada saat kadar hormon estrogen meningkat, tubuh bisa menjadi resisten terhadap insulin (Pelt et al., 2008). Semakin banyak jaringan lemak dalam tubuh, maka tubuh semakin resisten terhadap kerja insulin karena lemak dapat memblokir kerja insulin sehingga glukosa tidak dapat diangkut ke dalam sel dan menumpuk dalam pembuluh darah sehingga terjadi peningkatan kadar glukosa darah (Waris, 2015).

Lama menderita DM akan semakin meningkatkan terjadinya komplikasi berupa kerusakan pembuluh darah di seluruh tubuh sehingga makin memperberat gangguan fungsi organ-organ vital. Dalam rentang waktu yang cukup lama, kadar glukosa dalam darah akan merusak dinding pembuluh darah kapiler yang berhubungan langsung ke saraf. Menurut Smeltzer \& Bare (2008) lama menderita DM tipe II dapat menyebabkan terjadinya komplikasi. Penyebab yang spesifik dan patogenesis setiap jenis komplikasi masih terus diselidiki, namun peningkatan kadar glukosa darah tampaknya berperan dalam proses terjadinya kelainan neuropatik, komplikasi mikrovaskuler dan sebagai faktor resiko terjadinya komplikasi makrovaskuler. Seiring dengan komplikasi yang terjadi maka semakin lama durasi menderita DM maka semakin tinggi pula kejadian komplikasi yang dialami oleh penderita. Dalam jangka waktu yang cukup lama, kadar glukosa dalam darah akan merusak dinding pembuluh darah kapiler yang berhubungan langsung ke saraf.

Sesuai dengan karakteristik responden pada penelitian ini didapatkan bahwa sebesar $68,8 \%$ responden adalah lanjut usia, dimana usia sangat erat hubungannya dengan kenaikan kadar gula darah dan lama menderita DM, semakin bertambah usia maka gangguan toleransi glukosa juga akan semakin tinggi. Sehingga seseorang dengan diabetes melitus hanya dapat mempertahankan kadar gula dalam darah agar tetap normal, penyakit ini diderita seumur hidup.

Senam tai chi adalah suatu bentuk latihan atau seni untuk kesehatan fisik, keseimbangan jiwa dan mental, karena dengan melakukan senam secara teratur akan menyebabkan respon insulin menjadi sensitf sehingga kadar gula darah menurun. Tai chi merupakan jenis terapi non farmakologi yang dapat dilakukan untuk menurunkan kadar gula darah melalui peningkatan aktivitas fisik serta relaksasi. Secara teori relaksasi dapat menenangkan otak dan memulihkan tubuh, relaksasi yang dilakukan secara teratur dapat digunakan untuk menurunkan stress. Dengan relaksasi hipothalamus akan mengatur dan menurunkan aktifitas sistem saraf simpatis dan menyebabkan dilatasi arteriolar (Glickman \& Richard, 2007). 
Aktivitas fisik merupakan pergerakan tubuh yang menyebabkan pembakaran kalori, yang meliputi aktivitas sehari-hari dan berolahraga. Berolahraga dengan teratur dapat membantu menurunkan berat badan dan mengendalikan kadar gula darah. Olahraga akan memperbanyak jumlah dan meningkatkan aktivitas resptor insulin di dalam tubuh dan meningkatkan penggunaan glukosa. Menurut Nabyl (2012) prinsip dalam olahraga yaitu dilakukan dengan frekuensi waktu 3-5 kali dalam seminggu secara teratur, intensitas olahraga ringan dan sedang dengan durasi 30 - 60 menit setiap latihan, hal ini sejalan dengan penelitian yang dilakukan oleh peneliti dengan mengadakan senam tai chi seminggu 3 kali dengan durasi 60 menit setiap pertemuan. Hasil penelitian ini memperkuat penelitian sebelumnya mengenai perbedaan kadar gula darah sebelum dan sesudah intervensi senam Tai Chi pada pasien DM tipe II dalam menurunkan kadar gula darah yang dilakukan oleh Agik (2016) yang menunjukkan adanya hasil uji beda kadar glukosa darah sebelum dan sesudah pada kelompok intervensi dengan menggunakan uji Wilcoxon diperoleh nilai $\mathrm{p}$-value kelompok intervensi adalah $(0,000)<0,005$ dengan nilai rerata sebelum senam tai chi 157,00 dan sesudah tai chi 126,50. Penelitian ini juga sejalan dengan penelitian yang pernah dilakukan oleh Rehmaita et al., (2017) mengenai penurunan kadar gula darah sesudah pelaksanaan senam tai chi, berdasarkan uji statistik kadar gula darah sesudah perlakuan pada kelompok senam tai chi diperoleh nilai $p=0,000(p>0,05$ maka disimpulkan bahwa pemberian senam tai chi berpengaruh terhadap penurunan kadar gula darah pada pasien DM tipe 2.

Setelah diberikan senam DM kadar gula darah mengalami penurunan karena aktivitas olahraga sangat berpengaruh terhadap pengendalian kadar gula darah.Melakukan olahraga yang teratur dapat membuat peningkatan aliran ke otot dengan cara pembukaan kapilerpembuluh darah kecil diotot. Menurut Ilyas (2017) olahraga secara langsung bisa mengakibatkan terjadinya peningkatan pemakaian glukosa, sehingga reseptor insulin tersedia lebih banyak dan reseptor insulin menjadi lebih aktif, yang akan berpengaruh terhadap turunnya glukosa darah pada penderita diabetes sehingga terjadi perubahan pada kadar gula darah.

Menurut Sudoyo et al., (2006) Kegiatan fisik dinamik yang melibatkan kelompok otot-otot utama akan meningkatkan ambilan oksigen sebesar 15-20 kali liat karena peningkatan laju metabolic pada otot yang aktif. Ventilasi pulmoner dapat mencapai 100 L/ menit dan curah jantung meningkat hingga 20-30 L/menit, untuk memenuhi kebutuhan otot yang aktif . Terjadi dilatasi arteriol maupun kapiler yang menyebabkan lebih banyak jala-jala kapiler terbuka sehingga reseptor insulin lebih banyak dan lebih aktif/ lebih peka. Kepekaan reseptor insulin berlangsung lama bahkan sampai latihan telah berakhir. Jaringan otot yang aktif /peka insulin disebut jaringan non insulin dependent dan jaringan otot pada keadaan istirahat membutuhkan insulin untuk menyimpan glukosa, sehingga disebut jaringan insulin dependent, pada fase pemulihan post-exercise terjadi pengisian kembali cadangan glikogen otot dan hepar.Aktivitas glikogenik berlangsung terus sampai 12-24 jam post exercise, menyebabkan glukosa darah kembali normal (Ilyas, 2007).

Frekuensi senam penelitian ini memenuhi standar yaitu 3 kali dalam seminggu yang dilakukan dengan teratur. Penelitian ini sesuai dengan prinsip senam diabetes yang menyatakan untuk mencapai hasil yang optimal, latihan harus dilaksanakan secara teratur yaitu 3-5 kali perminggu dan tidak lebih 2 hari berurutan tanpa latihan, dimana salah satu pilar pengelolaan diabetes mellitus adalah latihan jasmani dengan durasi 30-60 menit, 
sehingga dapat memperbaiki kendali glukosa darah. Hasil dari penelitian ini seiringan dengan penelitian yang dilakukan oleh Erlina (2007) yang menyimpulkan intervensi senam DM yang dilakukan 3 kali dalam seminggu dapat menurunkan kadar gula darah pada penderita DM tipe II. Penelitian lain yang juga sejalan dengan penelitian ini adalah penelitian yang dilakukan oleh Andri (2016) yang menyatakan ada nya penurunan kadar gula darah setelah dilakukan intervensi senam diabetes sehingga disimpulkan terdapat perbedaan kadar gula darah sebelum dan setelah senam diabetes mellitus. Hasil penelitian yang dilakukan Rehmaita et al., ( 2017) menunjukkan adanya pengaruh yang signifikan terhadap penurunan kadar gula darah pada pasien diabetes mellitus type II dikarenakan kegiatan senam diabetes, dimana KGD pada masa sebelum aktivitas senam lebih tinggi dari setelah kegiatan senam diabetes.

Berdasarkan selisih rata-rata yang di dapat antara kelompok senam tai chi dan senam diabetes mellitus menunjukkan bahwa selisih penurunan kadar gula darah senam diabetes lebih besar dibandingkan dengan senam tai chi. Kadar gula darah dapat menurun apabila gula dalam darah diubah menjadi energy, sehingga tidak menumpuk dialiran darah yang membuat kadar gula darah tinggi. Pada penelitian ini kedua senam tersebut sama-sama berpengaruh dalam menurunkan kadar gula darah pada pasien DM tipe II, tetapi dilihat dari selisih penurunan kadar gula darah, senam DM lebih besar dari senam tai chi, selisih senam tai chi antara sebelum senam dan setelah senam yaitu $11,31 \mathrm{mg} / \mathrm{dl}$ sedangkan selisih senam DM antara sebelum dan setelah senam yaitu $23,37 \mathrm{mg} / \mathrm{dl}$.

Hal ini dipengaruhi karena pada kelompok senam tai chi ditemukan jumlah responden perempuan lebih banyak dibandingkan dengan senam diabetes mellitus, dimana perempuan setelah usia 30tahun memiliki risiko yang lebih tinggi dibanding pria. Menurut Damayanti perempuan lebih berisiko menderita diabetes dikarenakan secara fisik wanita memiliki peluang peningkatan indeks masa tubuh yang lebih besar, sindroma siklus bulanan (premenstrual syndrome), sesudah menopouse yang membuat pengantar lemak tubuh menjadi mudah terakumulasi akibat proses hormonal tersebut sehingga wanita berisiko menderita diabetes melitus tipe 2,dan diperkuat dengan hasil lama menderita diabetes pada kelompok tai chi lebih banyak di atas 5 tahun, dimana semakin lama sesorang menderita diabetes maka semakin besar kemungkinan seseorang untuk menderita komplikasi kronik makrovaskular (penyakit pembuluh darah besar), mengenai sirkulasi koroner, vaskular perifer dan vaskular serebral dan komplikasi kronik mikrovaskular (penyakit pembuluh darah kecil), mengenai mata (retinopati) dan ginjal (nefropati). Pada saat seseorang melakukan olahraga pada tubuh akan terjadi peningkatan kebutuhan bahan bakar tubuh oleh otot yang sedang aktif dan terjadi pula reaksi tubuh yang kompleks meliputi metabolisme, fungsi sirkulasi dan susunan saraf otonom. Dimana glukosa yang disimpan dalam otot dan hati sebagai glikogen, cepat diakses untuk dipergunakan sebagai sumber energy, setelah melakukan latihan jasmani selama 10 menit, akan terjadi peningkatan pemakaianglukosa 15 kali dari kebutuhan biasanya, setelah melakukan olahraga 60 menit terjadi peningkatan pemakaian glukosa sampai 35 kali.

Penurunan kadar glukosa darah partisipan juga dipengaruhi oleh tercapainya intensitas kedisiplinan yang baik selama intervensi senam dilakukan. Kondisi ini sesuai dengan konsep yang menjelaskan latihan akan bermanfaat jika mencapai kondisi optimal seseorang,yang meliputi tekanan darah sesudah latihan tidak lebih dari $180 \mathrm{mmHg}$ dan denyut nadi mencapai 60-79\% MHR. Jika denyut nadi kurang dari 60\% maka latihan bisa 
dikatakan kurang bermanfaat, dan jika lebih dari $79 \%$ akan membahayakan kesehatan pasien (Santoso, 2008). Pada saat melakukan latihan jasmani kerja insulin menjadi lebih baik dan yang kurang optimal menjadi lebih baik lagi. Akan tetapi efek yang dihasilkan dari latihan jasmani setelah 2 x 24 jam hilang, oleh karena itu untuk memperoleh efek tersebut latihan jasmani perlu dilakukan 2 hari sekali atau seminggu 3 kali (Suhartono, 2004). Hal ini dipengaruhi juga oleh senam diabetes merupakan senam yang aerobic low impact dan ritmis dengan gerakan yang mudah, tidak membosankandan bisa diikuti semua kelompok umur, dimana sebelumnya responden di puskesmas Menjalin sudah terbiasa dengan gerakan-gerakan yang ada di senam DM dibandingkan dengan senam tai chi (Santoso, 2008). Pada saat intervensi senam tai chi dan senam DM dilakukan peneliti memastikan bahwa responden tidak mendapatkan dan melakukan intervensi non farmakologis lainnya dalam upaya untuk menurunkan kadar gula darah, peneliti memastikan responden tidak melakukan terapi non farmakologis seperti relaksasi autogenic, akupresur, reiki dan senam kaki.

\section{SIMPULAN}

Karakteristik usia responden paling banyak menderita DM yaitu usia dari 45- 65 tahun, responden dengan jenis kelamin perempuan lebih banyak menderita DM dibandingkan dengan laki-laki, lama menderita DM responden paling banyak diatas 5 tahun. Senam Tai Chi dan senam diabetes mellitus sama-sama berpengaruh terhadap penurunan rata-rata kadar gula darah responden DM tipe 2. Terdapat perbedaan selisih rata-rata kadar gula darah 11,31 mg/dl sebelum dan sesudah intervensi pada kelompok senam Tai Chi. Terdapat perbedaan selisih rata-rata kadar gula darah 23,37 mg/dl sebelum dan sesudah intervensi senam diabetes mellitus.

\section{SARAN}

\section{Bagi Pelayanan Keperawatan}

Perawat dapat mengembangkan program senam Tai Chi dalam asuhan keperawatan pada pasien DM. Kepala Puskesmas dapat memprogramkan pengkombinasian pelaksanaan senam Tai Chi dan senam DM tiga kali dalam seminggu untuk hasil yang lebih efektif.

\section{Bagi Pendidikan Kesehatan}

Penelitian ini diharapkan bisa dijadikan tambahan ilmu pengetahuan keperawatan khususnya yang berkaitan dengan intervensi keperawatan dalam terapi non farmakologis.

\section{Bagi Peneliti Selanjutnya}

Bagi peneliti selanjutnya diharapkan bisa memperluas wilayah penelitian dengan menggunakan 2 puskesmas yang berbeda sehingga tingkat generalisasi lebih tinggi. Serta dapat meneliti lebih lanjut hubungan variabel perancu dengan penurunan kadar glukosa darah. 


\section{DAFTAR PUSTAKA}

ADA. (2010). Diagnosis and Classification of Diabetes Mellitus Diabetes Care USA. 27:55

Agik. P. N (2016). Pengaruh Tai Chi (TCD) terhadap Perubahan Tingkat Depresi dan Kadar Glukosa Darah pada Penderita Diabetes Mellitus Tipe II di wilayah Kelurahan Polehan Kota Malang. Universitas Muhammadiyah Malang

Andri, N. (2016). Kadar Gula Darah Sebelum dan Sesudah Melaksanakan Senam Diabetes pada Pasien Diabetes Melitus Tipe II. Jurnal Ilmu Kesehatan, IX(2)

Anwar, R. (2011). Bangkitkan Kekuatan Tai Chi dengan Shalatmu. Yogyakarta: DIVA Press

Brunner, B., \& Suddarth, S. (2008). Keperawatan Medikal Bedah.(edisi 8). Jakarta: EGC

Damayanti, L. (2010). Diabetes dan Hipertensi Wanita Lebih Beresiko: http://www.herbalitas.com

Glickman, G., \& Richard, R. (2007). Alternative Treatments for Hypertension. http://healthlibrary.epnet.com/print.as px?token=8482e079-8512-47c2-960 ca403 c77a5e4c\&chunkiid $=11764$

Hembing, W. (2008). Bebas Diabetes Mellitus Ala Hembing. Jakarta: Puspa Swara, Anggota IKAPI, 31, 45

Ilyas, E. I. (2017). Olahraga bagi Diabetisi, di dalam S.Soegondo et al (ed.), Penatalaksanaan Diabetes Mellitus Terpadu. Jakarta: FKUI

International Diabetes Federation. (2015). IDF Atlas Sixth Edition

Jelantik, G. M. G., \& Haryati, E. (2014). Hubungan Faktor Resiko, Jenis Kelamin, Kegemukan dan Hipertensi dengan Kejadian Diabetes Melitus Tipe II di Wilayah Kerja Puskesmas Mataram. Media Bina Ilmiah, 8(1), 39-44

Nabyl, R. A. (2012). Panduan Hidup Sehat : Mencegah dan Mengobati Diabetes Mellitus. Yogyakarta: Aulia Publising

Pelt, R. E., Schwartz, R. S., \& Kohrt, W. M. (2008). Insulin Secretion and Clearance after Subacute Estradiol Administration in Postmenopausal Women. Journal Clin Endocrinol Metabolisme, 93(2), 484-490. DOI: 10.1210/jc.2007-1657

Perkeni. (2011). Konsensus Pengelolaan dan Pencegahan Diabetes Melitus Tipe 2 di Indonesia. Jakarta: Perkeni

Perkeni. (2015). Pengelolaan dan Pencegahan Diabetes Melitus Tipe 2 di Indonesia. Jakarta: Perkeni

Pusdatin. (2014). Infodatin Pusat Data dan Informasi Kementrian Kesehatan RI. [Online] Available at:http: // www.depkes.go.id/resources/.../pusdatin/profil.../profilkesehatan-Indonesia-2015.pdf Diunduh Minggu 4 Maret 2018

Rehmaita, R., Mudatsir, M., \& Tahlil, T. (2017). Pengaruh Senam Diabetes dan Jalan Kaki terhadap Penurunan Kadar Gula Darah pada Pasien DM Tipe II di Puskesmas Krueng Barona Jaya Aceh Besar. Jurnal Ilmu Keperawatan, 5(2)

Rochmah, W. (2006). Diabetes Melitus pada Usia Lanjut, Buku Ajar Ilmu Penyakit Dalam, Edisi Ketiga, Editor Suyono, S., 1857. Jakarta: Balai Penerbit FKUI

Santoso, M. (2008). Senam Diabetes Seri 4. Jakarta: Yayasan Diabetes Indonesia

Smeltzer, S. C., \& Bare, B. G. (2008). Buku Ajar Kesehatan Medical Bedah, Volume 2, Edisi 8. Jakarta: Buku Kedokteran EGC 
Soegondo, S. (2009). Buku Ajar Penyakit Dalam: Insulin : Farmakoterapi pada Pengendalian Glikemia Diabetes Melitus Tipe 2, jilid III, Edisi 2. Jakarta: FK UI pp. 1884

Sudoyo, A. W., Bambang, S., \& Idrus, A. (2006). Buku Ajar Ilmu Penyakit Dalam. Jilid III, Edisi IV. Jakarta: FK-UI

Suhartono, T. (2004). Naskah Lengkap PB Persadia. Simposium Diabetes Melitus untuk Dokter dan Diabetisi. Semarang: Universitas Diponegoro, pp 25-31

Sujaya I. N. (2009). Pola Konsumsi Makanan Tradisional Bali sebagai Faktor Resiko Diabetes Melitus Tipe 2 di Tabanan. Jurnal Skala Husada, 6(1), 75-81

Waris, L. M. (2015). Kencing Manis (Diabetes Mellitus) di Sulawesi Selatan. ed Jakarta. Yayasan Pustaka Obor Indonesia 